\title{
Estimating benefits of therapy in Crohn's disease in terms of indirect costs
}

\author{
Subrata Ghosh MD FRCP FRCPE FRCPC
}

$\mathrm{H}$ ealth economic studies in Crohn's disease have generally estimated direct costs that are predominantly driven by hospitalization and surgery. Surgery and hospitalization account for approximately one-half of the direct costs (1). Eighty per cent of the societal costs of managing Crohn's disease are due to the $20 \%$ of the sufferers who are most severely affected. Introduction of monoclonal antibodies to treat Crohn's disease has increased the medical costs of management of Crohn's disease, but this may be offset by reduction of hospitalization and surgery. The Canadian data published from Manitoba predates the introduction and widespread use of biologics (2). However, indirect costs of Crohn's disease are less often estimated prospectively in the context of therapy. Economic analysis needs to be country specific because it is dependent on disease factors, health care costs, employment climate and wages, and societal attitude to chronic illness.

In the current issue of The Canadian Journal of Gastroenterology (pages 419-425), Panaccione et al (3) report on the Canadian openlabel Adalimumab in Canadian SubjeCts with ModErate to Severe Crohn's DiseaSe (ACCESS) trial with regard to therapeutic efficacy in moderate to severe Crohn's disease, which includes measures of work productivity estimated prospectively. It is important to have country-specific data because patient-reported health economic data may show considerable variation from country to country. The validated, self-administered Work Productivity and Activity Impairment Questionnaire (WPAI) was used at baseline before initiation of adalimumab therapy and at week 4 , week 12 , week 24 , and at 12 -week intervals subsequently until the conclusion of the study. Four components of work and the ability to perform activities of daily living were estimated: A. work time missed due to Crohn's disease (absenteeism); B. work productivity loss due to Crohn's disease (presenteeism); C. Total Work Productivity Impairment (TWPI=A+B); and D. Total Activity Impairment (TAI), which represents impairment of daily nonemployment activities. WPAI scores were reported as a percentage of overall impairment, with $0 \%$ being no Crohn's disease-related impairment and $100 \%$ representing total loss of work productivity or activity. In the ACCESS study, TWPI and TAI improved significantly as early as week 4. All four components of TWPI improved significantly, and substantially at week 24 .

The indirect costs of Crohn's disease in Canada are estimated to be nearly $\$ 600$ million and exceed the direct costs (4). Improvement of indirect costs consequent to therapy is, therefore, welcome. Allocation of scarce public resources needs to take into account benefits in terms of indirect costs. However, the methodology used to arrive at precise estimates is still controversial, and depends on methods of data collection, definition and philosophy. Community-based studies are different from hospital-based studies, and few studies can be generalized across different provinces or countries. In a chronic disease with considerable morbidity, such as Crohn's disease, one of the most significant benefits of effective and timely therapy is the reduction of indirect costs and gainful contribution to society. In addition, the psychological impact of such benefits in patient-reported outcomes is not to be underestimated (Box 1). Loss of leisure time is important, but rarely given an economic value; an estimate of the impact of therapy on these activities was measured in the ACCESS study by TAI.

In an era of intense debate about the appropriate therapeutic strategies to optimize the outcome of Crohn's disease, it is important to consider long-term patient-reported outcomes including indirect costs relevant to the society or the individual. In a disease characterized by recurrent cycles of flare-ups, tissue damage is cumulative and the disability is progressive. The best strategy to obtain maximum benefit on direct and indirect costs would likely include early intervention with effective treatment in patients predicted to have an aggressive disease course, complete remission of symptoms and intestinal inflammation, and prevention of relapses. However, long-term studies with validated measures of indirect costs as used in the ACCESS study are required.

\section{BOX 1}

Economic burden of chronic disease

1. Hospital inpatient care

2. Diagnostic tests and monitoring

3. Medical costs

4. Surgical costs

5. Inability to be productive and earn wages

6. Inability to acquire qualifications

7. Home care cost by family members

8. Premature mortality

9. Psychological costs of chronic disease

10. Loss of leisure time

CONFLICTS OF INTEREST: Dr S Ghosh has lectured at educational events and received honorarium from Merck, Abbott and Shire. He has received support for research from Merck and Abbott, and has participated in ad hoc advisory committees hosted by Merck, Abbott, Centocor, Pfizer, BMS and Shire.

\section{REFERENCES}

1. Odes S. How expensive is inflammatory bowel disease ? A critical analysis. World J Gastroenterol 2008;14:6641-7.

2. Bernstein CN, Papineau N, Jazaczkowski J, Rawsthorne P, Okrusko G, Blanchard JF. Direct hospital costs for patients with inflammatory bowel disease in a Canadian tertiary care university hospital. Am J Gastroenterol 2000;95:677-83.

3. Panaccione R, Loftus EV Jr, Binion D, et al. Efficacy and safety of adalimumab in Canadian patients with moderate to severe Crohn's disease: Results of the Adalimumab in Canadian SubjeCts with ModErate to Severe Crohn's DiseaSe (ACCESS) trial. Can J Gastroenterol 2011;25:419-25.

4. Crohn's and Colitis Foundation of Canada. The Burden of Inflammatory Bowel Disease (IBD) in Canada, 2008. <www.ccfc.ca> (Accessed on July 13, 2011).

\footnotetext{
Department of Medicine, University of Calgary, Foothills Medical Centre, Calgary, Alberta

Correspondence: Dr Subrata Ghosh, Department of Medicine, University of Calgary, Foothills Medical Centre, 1403-29th Street Northwest,

Calgary, Alberta. Telephone 403-944-8222, fax 403-944-1095, e-mail ghosh@ucalgary.ca

Received and accepted for publication July 14, 2011
} 


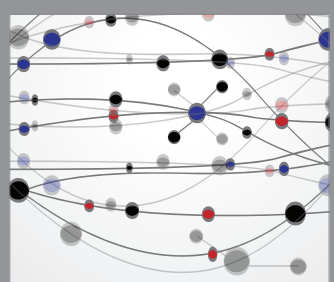

The Scientific World Journal
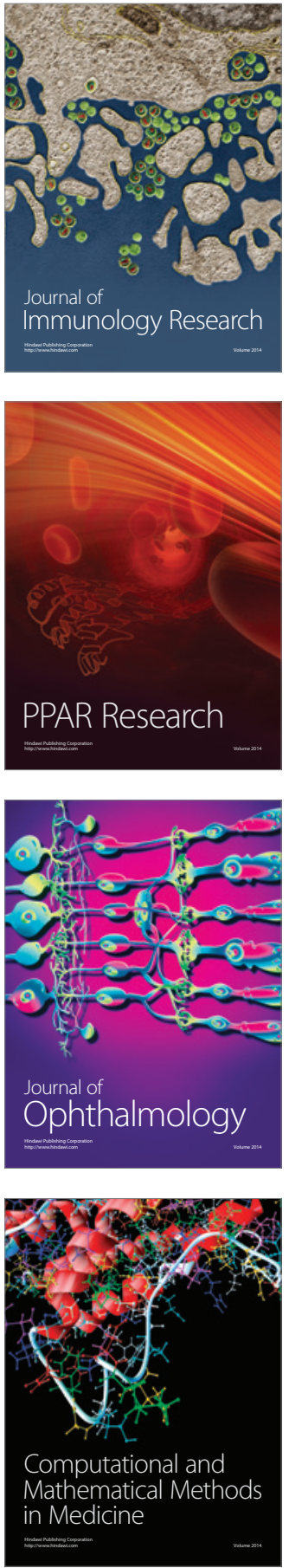

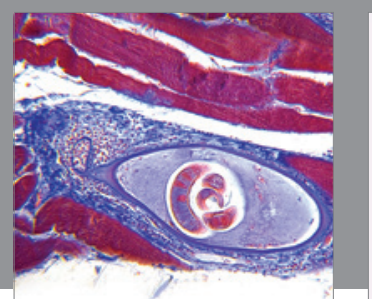

Gastroenterology Research and Practice

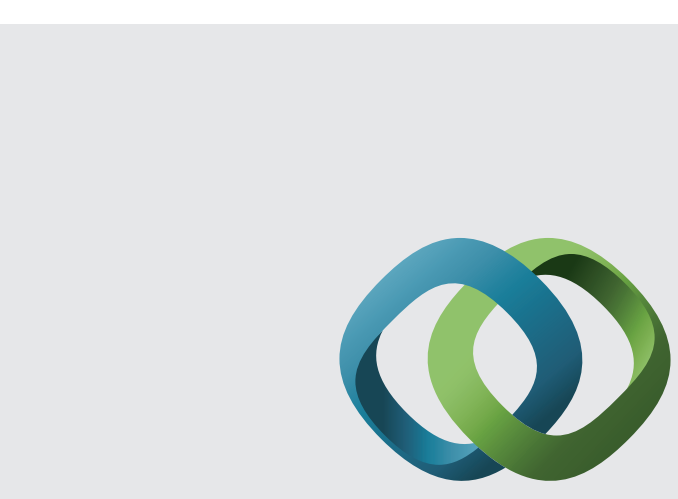

\section{Hindawi}

Submit your manuscripts at

http://www.hindawi.com
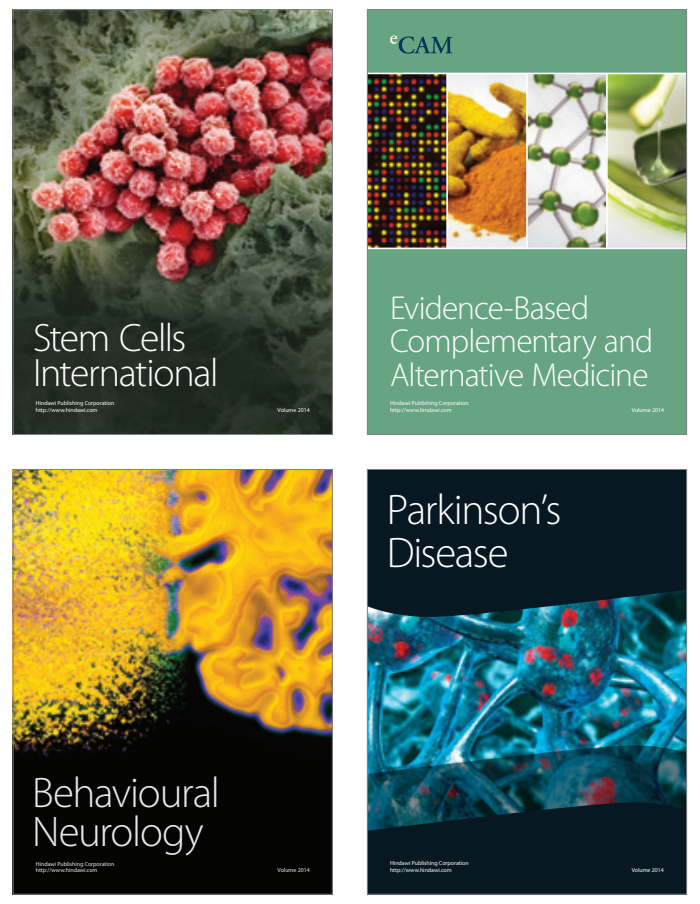
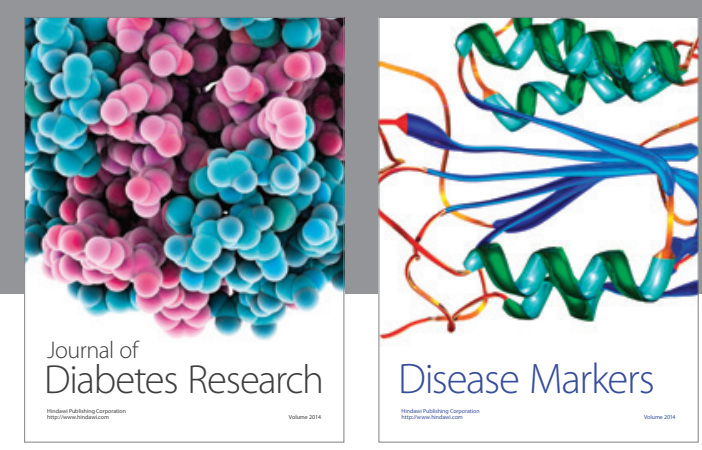

Disease Markers
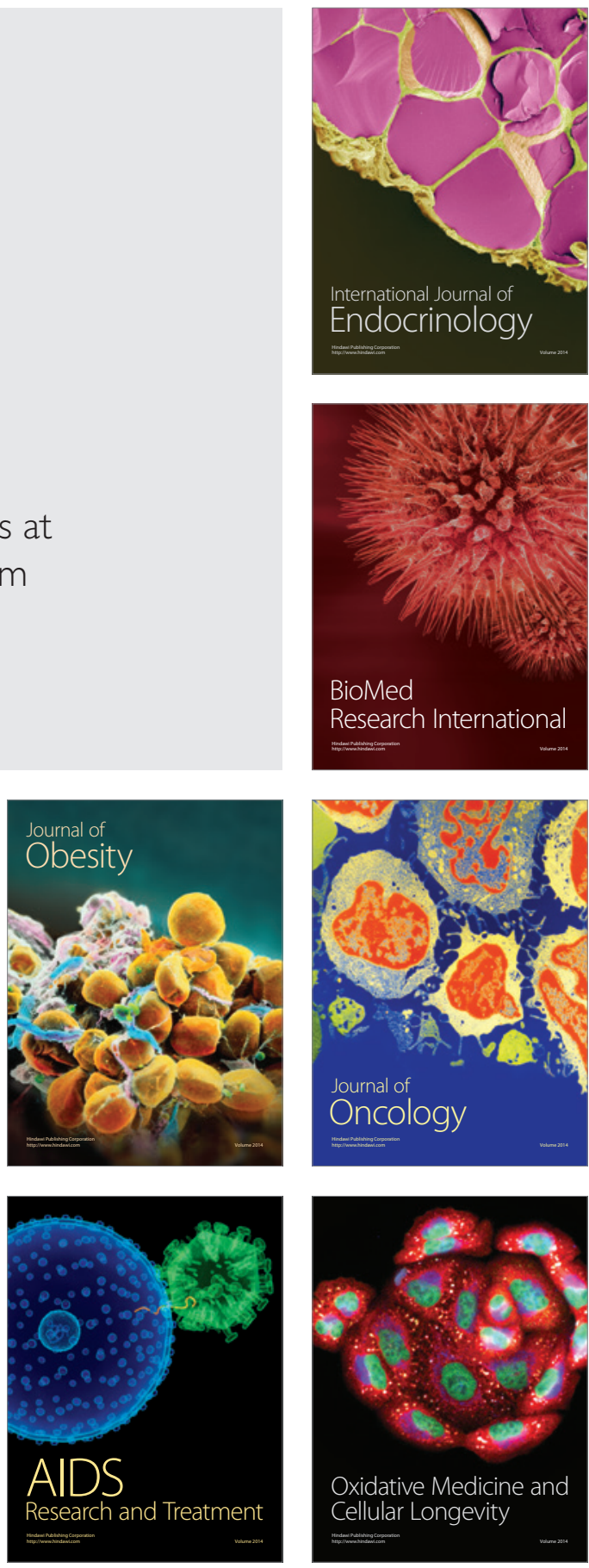